Plasma levels of TOS, TAS and OSI were significantly higher in patients with neonatal sepsis before therapy as compared to the control group ( $p<0.000, p<0.000$ and $p<0.000$, respectively) and plasma PON-1 level was significantly lower $(p<0.000)$. TAS levels in after treatment were significantly higher than in the control group ( $p=0.009$ ), while TOS, OSI and PON-1 levels were similar in after treatment compared to control group $(p=0.0 .078, p=0.597$, $\mathrm{p}=0.086$, respectively).

\section{COMPARISON OF URINARY NEUTROPHIL GELATINASE- ASSOCIATED LIPOCALIN, C-REACTIVE PROTEIN AND PROCALCITONIN IN DIAGNOSIS OF LATE ONSET SEPSIS IN PRETERM NEWBORNS}

doi:10.1136/archdischild-2012-302724.1183

'S Ertuğrul, ${ }^{2} \mathrm{R}$ Örs, ${ }^{3}$ S Kurban. ${ }^{1}$ Department of Neonatology; ${ }^{2}$ Konya University, Meram Medical Faculty; ${ }^{3}$ Department of Clinical Biochemistry, Konya University, Meram Medical Faculty, Konya, Turkey

Objective Urinary neutrophil gelatinase-associated lipocalin (uNGAL) has been suggested as a useful marker in limited recent studies for diagnosis of sepsis in pediatric and adult patients. We aimed to determine the value of uNGAL levels in early diagnosis of late-onset sepsis in preterms, and to compare CRP and PCT.

Materials and Methods Between February - May 2011, preterm infants admitted to NICU between the ages of 7 to 28 days divided into two groups: 24 cases with clinical sepsis (gestational age $32.88 \pm 1.45 \mathrm{w}$ ) and 20 cases as control group (gestational age $33 \pm 1.49 \mathrm{w})$.

Results There is no difference in two groups in terms of demographic features of babies. At 1. and 7. days of treatment in sepsis group, CRP (median:25.09mg/Lvs8.63mg/L),

PCT (median; $17.11 \mathrm{ng} / \mathrm{mlvs} 1.39 \mathrm{ng} / \mathrm{ml}$ )and uNGAL levels were found $45.69 \pm 18.37 \mathrm{ng} / \mathrm{ml}, 7.89 \pm 4.19 \mathrm{ng} / \mathrm{ml}$ respectively. In control group, uNGAL levels were found $5.78 \pm 1.6 \mathrm{ng} / \mathrm{ml}$. We found significant differences CRP, PCT and uNGAL levels between groups. On the seventh day of treatment, CRP, PCT and UNGAL levels significantly decreased.

We found that the sensitivity, specificity, positive and negative predictive values, respectively: for CRP; $58.3 \%, 80 \%, 77.8 \%$ and $61.5 \%$, for PCT; $91.7 \%, 75 \%, 81.5 \%$ and $88.2 \%$, for uNGAL; $91.7 \%$, $100 \%, 100 \%$ and $90.9 \%$.

Conclusion Urinary NGAL seems to be more sensitive and spesific, reliable biomarker than serum CRP and PCT. We believe that uNGAL unlike other biomarkers that does not require a blood sample, non-invasive and non-sterile conditions, with small amounts of urine collection in newborn sepsis might be an ideal biomarker.

\section{PRO-ADRENOMEDULLIN AS A PROGNOSTIC MARKER IN NEONATAL SEPSIS}

doi:10.1136/archdischild-2012-302724.1184

MY Oncel, U Dilmen, 0 Erdeve, R Ozdemir, E Calisici, S Yurttutan, FE Canpolat, SS Oguz, N Uras. Neonatology, Zekai Tahir Burak Maternity Teaching Hospital, Ankara, Turkey

Background and Aims The aim of this study was to investigate the value of pro-adrenomedullin (pro-ADM), as a marker of neonatal sepsis while comparing it with conventional markers of infection in newborns.

Methods Subjects were stratified into three groups; proven sepsis (Group 1a) and clinical sepsis (Group 1b) and the control group (Group 2) consisted of gestational age and birth weight matched newborns. Sequential measurements of white blood cell (WBC) count, C-reactive protein (CRP), interleukin-6 (IL-6) and pro-ADM were compared between groups.

Results A total of 76 patients with neonatal sepsis (31 with proven sepsis and 45 with clinical sepsis) and 52 healthy controls were enrolled. Mean baseline serum levels of CRP, IL-6 and pro-ADM were significantly higher in both Group $1 \mathrm{a}$ and Group $1 \mathrm{~b}$ compared to healthy controls $(p<0.001$ for both). Although mean baseline CRP and IL-6 levels were similar between groups, mean baseline pro-ADM level was higher in the proven sepsis group than the clinical sepsis group $(p<0.001)$.

Conclusion This is the first clinical study to investigate the value of pro-ADM for the diagnosis of proven and clinical sepsis in a newborn cohort including preterm newborns. Use of pro-ADM in combination with other acute phase reactants such as CRP and IL-6 for the diagnosis and follow-up of patients with neonatal sepsis has high sensitivity and specificity.

\section{NEUTROPHILE VOLUME, CONDUCTIVITY AND SCATTER PARAMETERS AND BETTER RESULTS WITH EMMA STATISTICAL PROGRAMIME IN NEONATAL SEPSIS}

doi:10.1136/archdischild-2012-302724.1185

1] Çelik, 'G Demirel, ${ }^{2} \mathrm{D}$ Sukhachev, ${ }^{1} 0$ Erdeve, ${ }^{1,3} \mathrm{U}$ Dilmen. 'Neonatology, Zekai Tahir Burak Maternity Teaching Hospital, Ankara, Turkey; ${ }^{2}$ LabTech LTD, Saint Petersburg, Russia; ${ }^{3 P e d i a t r i c s, ~ Y i l d i r i m ~ B e y a z i t ~ U n i v e r s i t y, ~ F a c u l t y ~ o f ~ M e d i c i n e, ~ A n k a r a, ~ T u r k e y ~}$

Introduction Current hematology analysers can determine cell volume $(V)$, conductivity for internal composition of cell(C) and light scatter for cytoplasmic granularity and nuclear structure(S) and standart deviations.

Method We investigated these parameters in secreening of neonatal sepsis beyond the first day of life. We used LH780 hematological analyzer(Beckman Coulter, Fullerton, CA). We combined these parameters with interleukin-6(IL-6) and C-reactive protein(CRP), and developed models to diagnose sepsis by Effective Modelling of Moleculer Activity(EMMA).

Results A total of 237 newborn, 61 proven sepsis, 108 clinical sepsis and 68 control, were enrolled the study. Mean neutrophil volume $(\mathrm{MNV})$ and volume distribution width(VDW) were found to be statistically increased both in proven and clinical sepsis groups. We developed models using MNV, VDV, IL- 6 and CRP. These models gave more sensitivity and specificity than usage of MNV, VDW, IL-6 and CRP alone.

Conclusion We suggest to use combination of MNV and VDW with markers such as CRP and IL-6, and use diagnostic models created by using EMMA including these markers.

Model 1: Sepsis $=-1.17+0.015^{*}[\mathrm{CRP}]+0.009^{*}[\mathrm{MNV}]$

Model 2: Sepsis $=-1.35+0.0136 *[\mathrm{CRP}]+0.0074 *[\mathrm{MNV}]+0.0123^{*}$

[VDW].

Model 3: Sepsis $=-0.94+0.0043 *[$ IL6 $]+0.011 *[$ CRP $]+0.0069 *[\mathrm{MNV}]$

Table 2. Test results and models' performance of sepsis group

Parameter Cut-off Sens Spec 95\% Confidence Interval

MNV (au) $>157.178 .6481 .630 .807$ to 0.890

VDW (au) $>37.459 .7177 .550 .687$ to 0.789

IL6 $(\mathrm{pg} / \mathrm{mL})>1881.7692 .650 .869$ to 0.945

CRP (mg/dL) >7.5 71.5798 .530 .852 to 0.928

Model $1>0.309988 .7392 .650 .921$ to 0.975

Model $2>0.361587 .7592 .650 .912$ to 0.970

Model $3>0.242995 .8691 .180 .950$ to 0.992

\section{DOES AVAILABILITY OF INTERLEUKIN-6 RESULTS INFLUENCE CLINICAL DECISION MAKING IN NEONATAL SEPSIS?}

doi:10.1136/archdischild-2012-302724.1186

1,2S Babarao, 'L Miall. 'Neonatal Unit, Leeds Teaching Hospitals NHS Trust; ${ }^{2}$ School of Paediatrics, University of Leeds, Leeds, UK

Backround and aims Clinical diagnosis of neonatal sepsis has always been challenging. Recent studies have suggested that 